https://helda.helsinki.fi

\title{
Prolonged low-molecular-weight heparin use during pregnancy and subsequent bone mineral density
}

\section{Galambosi, Päivi}

2016-07

Galambosi , P , Hiilesmaa , V , Ulander , V-M , Laitinen , L , Tiitinen , A \& Kaaja , R 2016 , '

Prolonged low-molecular-weight heparin use during pregnancy and subsequent bone

mineral density ' , Thrombosis Research, vol. 143 , pp. 122-126 . https://doi.org/10.1016/j.thromres.2016.05.016

http://hdl.handle.net/10138/224077

https://doi.org/10.1016/j.thromres.2016.05.016

publishedVersion

Downloaded from Helda, University of Helsinki institutional repository.

This is an electronic reprint of the original article.

This reprint may differ from the original in pagination and typographic detail.

Please cite the original version. 
Full Length Article

\title{
Prolonged low-molecular-weight heparin use during pregnancy and subsequent bone mineral density is
}

\author{
Päivi Galambosi ${ }^{\text {a,* }}$, Vilho Hiilesmaa ${ }^{a}$, Veli-Matti Ulander ${ }^{a}$, Leena Laitinen ${ }^{\text {a }}$, Aila Tiitinen ${ }^{\text {a }}$, Risto Kaaja ${ }^{\text {b }}$ \\ a University of Helsinki, Helsinki University Hospital, Department of Obstetrics and Gynaecology, Haartmaninkatu 2, 00290 Helsinki, Finland \\ ${ }^{\mathrm{b}}$ University of Turku and Turku University Central Hospital, Kiinamyllynkatu 4-8, 20520 Turku, Finland
}

\section{A R T I C L E I N F O}

\section{Article history:}

Received 23 February 2016

Received in revised form 29 April 2016

Accepted 18 May 2016

Available online 19 May 2016

\section{Keywords:}

Low-molecular-weight heparin

Bone mineral density

Pregnancy

Osteoporosis

Osteopenia

Risk factors

\begin{abstract}
A B S T R A C T
Introduction: In contrast to unfractionated heparin (UFH), use of low-molecular weight heparin (LMWH) during pregnancy has not been reported to be associated with a significant decrease in bone mineral density (BMD). The aim of this study was to investigate whether long-term use of LMWH during pregnancy is associated with subsequent decrease in BMD or with increased number of osteoporotic fractures.

Materials and methods: In this observational cohort study BMD was measured by dual energy X-ray absorptiometry (DEXA) 4-7 years after the last delivery in 152 women. Ninety-two women had prolonged LMWH-exposure during pregnancy - 75 as prophylaxis and 17 as treatment for venous thromboembolic event (VTE). Dalteparin and enoxaparin were the LMWH-preparations used. Sixty women without LMWH-exposure served as controls. A questionnaire about lifestyle factors and medical history was filled out by the subjects.

Results: Lumbar spine BMD in the LMWH users was lower than that in the controls both in the prophylactic group $\left(1.22 \mathrm{~g} / \mathrm{cm}^{2}\right.$ vs. $\left.1.27 \mathrm{~g} / \mathrm{cm}^{2} ; \mathrm{p}=0.03\right)$, and in the treatment group $\left(1.20 \mathrm{~g} / \mathrm{cm}^{2}\right.$ vs. $\left.1.27 \mathrm{~g} / \mathrm{cm}^{2} ; \mathrm{p}=0.07\right)$. BMD in femoral neck did not differ between the LMWH-users and controls. However, after adjusting for potential confounding factors, LMWH-exposure did not remain associated with decreased BMD in lumbar spine. Use of contraceptive pills was positively associated with BMD in lumbar spine. Incidence of osteopenia was 13\% in the LMWH-group and $8 \%$ in the control-group, $(\mathrm{p}=0.4)$. No osteoporosis or osteoporotic fractures were found. Conclusions: Prolonged use of LMWH during pregnancy was not associated with subsequent decrease in BMD, osteopenia, osteoporosis, or osteoporotic fractures.
\end{abstract}

(c) 2016 Elsevier Ltd. All rights reserved

\section{Introduction}

Since 1980s LMWH has replaced UFH in prevention and treatment of VTE during pregnancy and prevention of recurrent pregnancy loss in women with antiphospholipid antibodies. [1-4] It is still unclear to which extend prolonged use of LMWH is associated with adverse effects earlier reported for UFH, such as heparin-induced thrombocytopenia (HIT), bleeding and heparin-induced osteoporosis (HIO) [4-10]. Pregnancy besides cancer is one of the few situations, where prolonged heparin use is recommended if indicated [11].

Osteoporosis is a systemic skeletal disease characterized by low bone mass and micro-architectural alterations associated with increased bone fragility and consequent increase in risk of fractures [12]. BMD is expressed either as an absolute value $\left(\mathrm{g} / \mathrm{cm}^{2}\right)$ or as a T- or Z-

\footnotetext{
is Presented as a poster at ISTH (International Society on Thrombosis and Haemostasis) in Toronto June 24th 2015

* Corresponding author.

E-mail addresses: paivi.galambosi@gmail.com (P. Galambosi), hiilesmaa@gmail.com (V. Hiilesmaa), veli-matti.ulander@hus.fi (V.-M. Ulander), leena.laitinen@hus.fi

(L. Laitinen), aila.tiitinen@hus.fi (A. Tiitinen), riskaa@utu.fi (R. Kaaja).
}

score. T-score measures the difference, by number of standard deviations, of an individual BMD from the mean of young female reference population [12]. Osteoporosis is diagnosed when T-score is -2.5 or less, and osteopenia (decreased bone density), when T-score is between -2.5 and -1 [12]. Z-score, in turn, is the number of standard deviations by which a patient's BMD differs from the average BMD of the same age, sex and ethnicity [12].

Bone loss associated with UFH is due to decreased bone formation and increased bone resorption [13] and could explain 2-9\% experience of symptomatic fracture after prolonged UFH-use during pregnancy [6, 14]. LMWH might cause less osteoporotic effect by acting only on bone formation [15].

The number of pregnant women using LMWH is growing and the risks of long-term LMWH-use are important to investigate. Pregnant women are mainly young, thus other risk factors for osteoporosis are rare in this population, but prolonged use of LMWH could lead to lower bone mass, becoming relevant when these women were going to enter postmenopausal phase [12].

Our aim was to study whether there is subsequent decrease of BMD in lumbar spine and/or femoral neck after a long-term use of LMWH during pregnancy. 


\section{Material and methods}

This observational cohort study was undertaken at the Department of Obstetrics and Gynecology, Helsinki University Central Hospital, Finland. The study group (LMWH-group) included 92 women, who received LMWH-prophylaxis or -treatment during their pregnancy. Fifteen women in the LMWH-group had a history of two LMWH-exposed pregnancies. Sixty women without LMWH-exposure served as controls. Participants were invited to the study by a recruitment letter, which included information about the marginal radiation associated with DEXA analysis. A total of 190 recruitment letters were sent to the LMWH-exposed patients and 380 to potential controls. Our primary aim was to select two controls for every case, matched for age and parity. Unfortunately many potential controls declined from DEXA, and thus we succeeded to recruit just 60 controls. Subjects were identified in the electronic hospital database by using International Classification of Diseases-10 (ICD10) codes I73, I74, I80, I81, I82, I83, D68 and M32. The consecutive parity-matched next parturient after the index case without LMWH-exposure was selected as a control. All subjects were Caucasians. Approval was obtained from the local ethics committee.

BMD in lumbar spine and femoral neck was measured with DEXA (Lunar Prodigy advance Full Size, encore software Version 15. GE Medical Systems-Lunar Madison. WI USA). The DEXA was carried out 4 years (median) after the last delivery in LMWH-group and 7 years (median) after the last delivery in control-group. The women were asked to fill out a questionnaire regarding their lifestyle factors (smoking, physical exercise, dietary calcium intake and alcohol use) and medical history, such as, menstrual cycle, underlying diseases, medications, duration of breastfeeding and contraception. The baseline characteristics (age, BMI, gravidity, parity, obstetric history and medical history including regular medication) as well as the data on the type of $\mathrm{LMWH}$, dosing details, time of initiation and duration of the use were retrieved from the electronic hospital database. The calculated total LMWH-dose included all dosages received in all pregnancies together.

The women in the LMWH-group received either dalteparin or enoxaparin. We did not collect the individual exact indications of LMWH-use, other than above mentioned ICD10-codes used to identify LMWH-exposed women, because those were estimated to be irrelevant in terms of the risk of osteoporosis. Normal prophylactic LMWH-doses were standardized: enoxaparin $40 \mathrm{mg} /$ day or dalteparin $5000 \mathrm{IU} /$ day. Weight-adjusted treatment doses were defined as full-treatment doses of LMWH (dalteparin $200 \mathrm{IU} / \mathrm{kg} /$ day or enoxaparin $1 \mathrm{mg} / \mathrm{kg}$ twice daily). Intermediate doses were $50 \%$ of weight-adjusted treatment doses, i.e. enoxaparin $1 \mathrm{mg} / \mathrm{kg} /$ day or dalteparin $100 \mathrm{IU} / \mathrm{kg} /$ day. The total LMWH-dose during all pregnancies was also calculated.

We approximated the daily calcium intake based on declared calcium-containing food consumption by using Fineli ${ }^{\circledR}$ nutrient composition database [16]. Long-term (>6 months) oral glucocorticoids [17] and antiepileptics [18] were determined as significant medications in terms of osteoporosis risk. Diseases which affect calcium metabolism, for example, primary hyperparathyroidism, Cushing disease, chronic liver, kidney and gastrointestinal (for example celiac disease) diseases and rheumatoid arthritis type diseases were determined as significant diseases in terms of osteoporosis risk [19,20].

The principal outcome variable was BMD in lumbar spine and femoral neck, T-scores and Z-scores were also calculated. Secondary outcome variables included established osteoporosis (T-score $<-2.5$ ) and osteopenia $(-1.0<$ T-score $>-2.5)$ and clinically evident osteoporotic fractures. The null hypothesis was, that there is no difference in BMD between LMWH- and control groups at p-level $<0.05$. In LMWH-exposed women DEXA-measurement was performed between years 2008 and 2009. Due to delayed funding, DEXA in the control women was carried out between years 2011 and 2012, causing an age difference between LMWH-exposed woman and controls at time of DEXA-analysis. All DEXA-measurements were made by single equipment. The quality assurance of our equipment was performed by daily calibrations and weekly accuracy measurements. During the years 2008-2012 daily calibrations were carried out by using a standard calibration block which includes 3 cavities that simulate the BMD-values $0.5,1.0$ and $1.5 \mathrm{~g} /$ $\mathrm{cm}^{2}$. The BMD of every cavity must be within $0.03 \mathrm{~g} / \mathrm{cm}^{2}$ of the expected value. Repeatability accuracy over the long term was adjusted through weekly measurements by using a skeleton phantom (Accuracy Phantom, SN 21979, BMD $1.265 \mathrm{~g} / \mathrm{cm}^{2}$ ). The day to day variation of our equipment is $0.01 \mathrm{~g} / \mathrm{cm}^{2}$ and the coefficient of variation is $1.0 \%$ (\%CV = standard deviation/a percentage of average-BMD) for lumbar spine and femoral neck.

Statistical Package for the Social Sciences Versions 21 and 23 (SPSS Inc., Chicago, IL, USA) were used for analyses. Continuous variables were tested by Student's $t$-test, when normally distributed, else by Mann-Whitney $U$ test. Frequencies were compared by Chi-squared test. Dose-effect was calculated by using linear regression. Multivariate regression analysis was used to adjust outcome variables for potential confounding factors. Women with missing values in one or more variables were excluded from the multivariate regression analysis. All tests were two-tailed and $\mathrm{p}$-values $<0.05$ were considered as statistically significant. In order to achieve $80 \%$ power, number needed for both arms was originally calculated to be 80 to detect a $10 \%$ difference in BMD between the study groups.

\section{Results}

The demographics of the study participants are shown in Table 1. Three women did not answer to the questionnaire. One woman did not report her daily calcium-containing food consumption and one woman did not report the amount of her physical exercise per week. Five women did not remember their menarche age and four their duration of lactation, additionally 30 women forgot their menstruation onset time after childbirth. Otherwise questionnaires were complete.

Ten women (10.9\%) had weight-adjusted treatment doses and seven women $(7.6 \%)$ had intermediate doses, the rest 75 women (81.5\%) had prophylactic doses of LMWH. The percentage of the

Table 1

Demographics of the study participants.

\begin{tabular}{|c|c|c|c|}
\hline & LMWH-group & Control-group & p-Value \\
\hline & $\mathrm{n}=92$ & $\mathrm{n}=60$ & \\
\hline Age (years); mean (SD) & $38.4(4.9)$ & $43.4(4.3)$ & $<0.001$ \\
\hline BMI $\left(\mathrm{kg} / \mathrm{m}^{2}\right) ;$ mean $(\mathrm{SD})$ & $24.0(4.7)$ & $25.7(4.8)$ & 0.03 \\
\hline $\begin{array}{l}\text { Years after the last delivery; median } \\
\text { (range) }\end{array}$ & $3.7(1-11)$ & $6.8(4-12)$ & $<0.001$ \\
\hline Primiparous (\%) & 29.3 & 33.3 & 0.72 \\
\hline $\begin{array}{l}\text { Total duration of LMWH (days) }{ }^{\mathrm{a}} \text {; mean } \\
\text { (SD) }\end{array}$ & $247(84)$ & 0 &. \\
\hline \multicolumn{4}{|l|}{ Total LMWH-dose; median (range) } \\
\hline Dalteparin $\left(\mathrm{IU} * 10^{3}\right), \mathrm{n}=39$ & $\begin{array}{l}1260 \\
(158-3028)\end{array}$ & 0 & .. \\
\hline Enoxaparin $\left(\mathrm{mg} * 10^{3}\right), \mathrm{n}=53$ & $\begin{array}{l}9.8 \\
(2.5-35.1)\end{array}$ & 0 & .. \\
\hline Ever smoked (\%) & 41.6 & 35.0 & 0.5 \\
\hline $\begin{array}{l}\text { Alcohol doses per week; median } \\
\quad \text { (range) }\end{array}$ & $2.0(0-24)$ & $2.5(0-17)$ & 0.9 \\
\hline Dietary calcium intake (mg); mean (SD) & $740(351)$ & $670(331)$ & 0.3 \\
\hline $\begin{array}{l}\text { Physical exercise (hours/week); mean } \\
\text { (SD) }\end{array}$ & $2.3(1.2)$ & $2.0(1.5)$ & 0.3 \\
\hline Chronic diseases $^{\mathrm{b}}(\%)$ & 4.5 & 5.0 & 0.9 \\
\hline Menarche (years), mean (SD) & $12.7(1.4)$ & $12.7(1.4)$ & 0.8 \\
\hline $\begin{array}{l}\text { Duration of lactation (months per each } \\
\text { birth); median (range) }\end{array}$ & $7.5(0-24)$ & $8.5(0-32)$ & 0.6 \\
\hline $\begin{array}{l}\text { Onset of menstruation after childbirth } \\
\text { (months); median (range) }\end{array}$ & $5(1-14)$ & $4(1-18)$ & 0.9 \\
\hline $\begin{array}{l}\text { Oral contraception pill use (years); } \\
\text { median (range) }\end{array}$ & $7(0-24)$ & $10(0-26)$ & 0.02 \\
\hline Previous bone fracture (\%) & 32.6 & 28.3 & 0.6 \\
\hline
\end{tabular}

a All LMWH-exposed pregnancies together (antepartum and postpartum use).

b Four rheumatoid type diseases (LMWH-group). One lymphocytic hypophysitis, one ulcerative colitis and one celiac disease (control-group). 
enoxaparin-users was 58\% and the dalteparin-users $42 \%$. Mean duration of the use of prophylactic LMWH-doses was 216 days (minimum 28 days and maximum 294 days) and the use of weight-adjusted treatment doses or intermediate doses was 218 days (minimum 70 days and maximum 280 days). One woman who initially received weight-adjusted treatment dose changed her dose to intermediate one, and one woman, who originally received weight-adjusted treatment dose changed her dose to prophylactic one during the later pregnancy. The total dalteparin-dose was slightly $<1.3$ million international units (IU) and enoxaparin-dose was slightly $<10,000$ milligrams ( $\mathrm{mg}$ ). The controls were statistically significantly older and heavier than the women in the LMWH-group at the time of DEXA-analysis. The groups did not differ in terms of lifestyle and medical history aside from duration of contraceptive pill use. Minority of the woman in both groups had some significant disease in terms of osteoporosis risk. Four women in the LMWH-group had rheumatoid arthritis type diseases (systemic lupus erythematosus, Sjögren's syndrome, juvenile rheumatoid arthritis and arthrosis), but none of them required oral glucocorticoids. No women received long-term vitamin $\mathrm{K}$ antagonists before or after the pregnancy. Six women received continuous aspirin. In control group one woman had lymphocytic hypophysitis requiring oral glucocorticoids, one woman had ulcerative colitis, not requiring oral glucocorticoids, and one woman had celiac disease.

Table 2 shows BMD and T- and Z-scores in LMWH-users (prophylactic dose and weight-adjusted treatment dose plus intermediate dose separately) and controls. BMD in spine was lower both in women with prophylactic $(\mathrm{p}=0.03)$ and weight-adjusted treatment/intermediate $(p=0.07)$ LMWH doses. There was no difference between the dalteparin and enoxaparin-users in BMD in lumbar spine, $(p=0.28)$, neither in femoral neck ( $p=0.65)$. No correlation between BMD in lumbar spine and total dose of dalteparin or enoxaparin was found, even though the ranges of the LMWH-doses were broad.

Twelve women in the LMWH-group (13.0\%) and 5 women in the control group (8.3\%) had osteopenia, but this difference was not significant between the groups $(\mathrm{p}=0.40)$. We compared the osteopenic women with non-osteopenic women in terms of all variables occurring in Table 1. Only BMI and duration of contraception pill use differed significantly between the groups. BMI (osteopenic vs. non-osteopenic $21.4 \mathrm{~kg} / \mathrm{m}^{2}$ vs. $25.1 \mathrm{~kg} / \mathrm{m}^{2} ; \mathrm{p}=0.000$ ) and duration of contraception pill use (osteopenic vs. non-osteopenic 5.6 years vs. 5.8 years; $\mathrm{p}=$ 0.02 ). No osteoporosis or osteoporotic fractures was observed in this population. BMD was normal in woman, who received oral glucocorticoids.

BMDs in lumbar spine are shown graphically in women, who received prophylactic LMWH-doses, weight-adjusted treatment- or intermediate LMWH-doses and controls separately (Fig. 1).

The multivariate regression analysis was performed separately for those with prophylactic LMWH-dose compared to controls and for those with weight-adjusted treatment- or intermediate LMWH-dose compared to controls (Table 3a and b). It showed that, after adjustment for potential confounding factors, LMWH-exposure during pregnancy

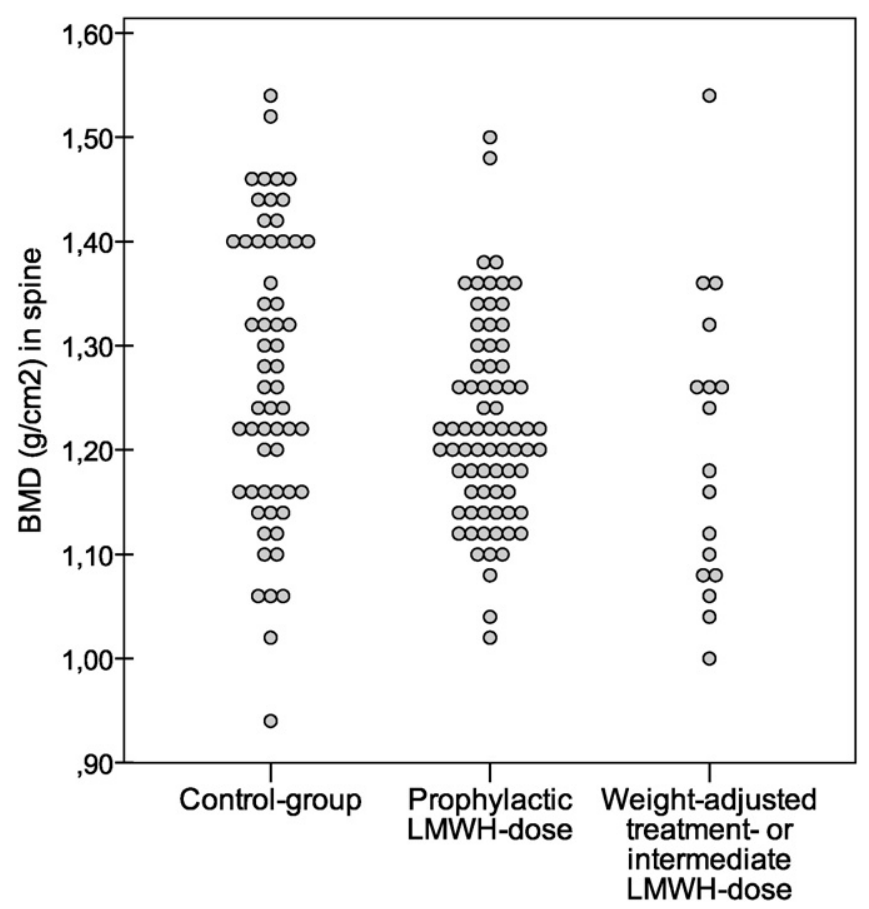

Fig. 1. BMDs in lumbar spine in women, who received prophylactic LMWH-doses, weightadjusted treatment- or intermediate LMWH-doses and controls.

did not remain significantly associated with decreased BMD in lumbar spine.

In contrast, duration of contraception pill use was independently associated with greater BMD ( $\beta$ Coefficient (prophylactic LMWH-dose as an independent variable $)=0.19 ; \mathrm{p}=0.04)$. We did not find any statistically significant association between BMD in lumbar spine and BMI, age, smoking, calcium intake, physical exercise, duration of lactation and time since last delivery.

\section{Discussion}

Our results suggest, that long-term prophylactic LMWH-use during pregnancy is not associated with a subsequent decrease of BMD in lumbar spine when adjusted for potential confounders. The incidence of osteopenia did not differ significantly between the LMWH-group and the control-group. No osteoporosis or osteoporotic fractures was observed. Lack of correlation between LMWH-dose and BMD supports this conclusion. Presumably, because of the small sample size, no statistically significant difference in lumbar spine BMD existed between the women, who received weight-adjusted treatment- or intermediate dose of LMWH and controls.

Studies with comparison of the impact of LMWH and UFH on BMD in pregnant women have so far given inconsistent results. Two studies

Table 2

BMD, T- and Z-scores in LMWH-group vs. control-group.

\begin{tabular}{|c|c|c|c|c|c|}
\hline & \multicolumn{2}{|l|}{ LMWH-group } & \multirow[b]{3}{*}{ Control-group $n=60$} & \multirow[b]{3}{*}{ p-Value ${ }^{a}$} & \multirow[b]{3}{*}{ p-Value ${ }^{b}$} \\
\hline & Prophylactic dose & Weight-adjusted/intermediate dose & & & \\
\hline & $\mathrm{n}=75$ & $\mathrm{n}=17$ & & & \\
\hline BMD spine $\left(\mathrm{g} / \mathrm{cm}^{2}, \mathrm{SD}\right)$ & $1.22(0.09)$ & $1.20(0.14)$ & $1.27(0.14)$ & 0.03 & 0.07 \\
\hline T-score spine (SD) & $0.43(0.79)$ & $0.22(1.19)$ & $0.83(1.15)$ & 0.02 & 0.06 \\
\hline Z-score spine (SD) & $0.44(0.80)$ & $0.23(1.18)$ & $0.93(1.16)$ & 0.007 & 0.03 \\
\hline BMD femoral neck $\left(\mathrm{g} / \mathrm{cm}^{2}, \mathrm{SD}\right)$ & $0.99(0.11)$ & $1.0(0.15)$ & $1.01(0.12)$ & 0.39 & 1.0 \\
\hline T-score femoral neck (SD) & $0.09(0.91)$ & $0.18(1.18)$ & $0.24(0.97)$ & 0.39 & 0.85 \\
\hline Z-score femoral neck (SD) & $0.2(0.91)$ & $0.28(1.20)$ & $0.43(0.96)$ & 0.15 & 0.58 \\
\hline
\end{tabular}

BMD, bone mineral density; SD, standard deviation.

a Women, who received prophylactic LMWH-dose vs. control-group.

b Women, who received weight-adjusted- or intermediate LMWH-dose vs. control-group. 
Table 3

$\mathrm{a}$ and b: Associations of lumbar spine BMD $\left(\mathrm{g} / \mathrm{cm}^{2}\right)$ with LMWH and potential confounders: Multivariate regression analysis. Dependent variable is BMD in lumbar spine.

\begin{tabular}{|c|c|c|c|}
\hline \multirow[t]{2}{*}{ Independent variable } & \multicolumn{2}{|c|}{$\beta$ coefficient } & \multirow[t]{2}{*}{ p-Value } \\
\hline & Value & SE & \\
\hline \multicolumn{4}{|c|}{$\begin{array}{l}\text { a. Associations of lumbar spine BMD }\left(\mathrm{g} / \mathrm{cm}^{2}\right) \text { with } L M W H \text { (prophylactic dose) and } \\
\text { potential confounders }(n=131 \text { with complete data) }\end{array}$} \\
\hline \multicolumn{4}{|c|}{$R^{2}=0.103$} \\
\hline LMWH (prophylactic) & -0.13 & 0.026 & 0.26 \\
\hline Age during DEXA-measurement (years) & -0.19 & 0.002 & 0.08 \\
\hline $\mathrm{BMI}\left(\mathrm{m} / \mathrm{kg}^{2}\right)$ & 0.11 & 0.002 & 0.23 \\
\hline Ever smoked (yes or no) & -0.06 & 0.023 & 0.50 \\
\hline Calcium intake (mg) & 0.04 & $<0.001$ & 0.68 \\
\hline Physical exercise (h/week) & 0.08 & 0.008 & 0.36 \\
\hline Duration of contraception pill use (years) & 0.19 & 0.002 & 0.04 \\
\hline Duration of lactation (months) & -0.005 & 0.002 & 0.95 \\
\hline Time since last delivery (years) & 0.16 & 0.005 & 0.15 \\
\hline \multicolumn{4}{|c|}{$\begin{array}{l}\text { b. Associations of lumbar spine BMD }\left(\mathrm{g} / \mathrm{cm}^{2}\right) \text { with } \mathrm{LMWH} \text { (weight-adjusted } \\
\text { treatment- or intermediate dose) and potential confounders ( } n=73 \text { with complete } \\
\text { data) }\end{array}$} \\
\hline \multicolumn{4}{|c|}{$R^{2}=0.163$} \\
\hline LMWH (treatment/intermediate) & -0.17 & 0.053 & 0.24 \\
\hline Age during DEXA-measurement (years) & -0.18 & 0.004 & 0.20 \\
\hline $\mathrm{BMI}\left(\mathrm{m} / \mathrm{kg}^{2}\right)$ & -0.05 & 0.004 & 0.74 \\
\hline Ever smoked (yes or no) & -0.13 & 0.037 & 0.29 \\
\hline Calcium intake (mg) & -0.07 & $<0.001$ & 0.57 \\
\hline Physical exercise (h/week) & 0.02 & 0.01 & 0.85 \\
\hline Duration of contraception pill use (years) & 0.25 & 0.003 & 0.05 \\
\hline Duration of lactation (months) & 0.05 & 0.003 & 0.65 \\
\hline Time since last delivery (years) & 0.21 & 0.008 & 0.12 \\
\hline
\end{tabular}

BMD, bone mineral density; LMWH, low-molecular-weight heparin; $\mathrm{R}^{2}$, R Square; SE, standard error; DEXA, dual-energy X-ray absorptiometry.

reported 2.0-3.7\% reduction in BMD with no difference between LMWH and UFH $[10,21]$. According to a review with 11 cases of LMWH-induced osteoporotic fractures eight of those occurred during pregnancy [22]. A recent report presented two cases with multiple osteoporotic vertebral compression fractures in postpartum period, both women were treated with enoxaparin throughout their pregnancy [23].

A randomized study with 44 pregnant women on prophylactic doses either UFH or dalteparin stated that mean BMD of the lumbar spine during pregnancy and puerperium was significantly lower in UFH group, with two symptomatic compression fractures in it, whereas in the dalteparin-group, BMD did not differ from that of healthy delivered women [6].

Another randomized study with 33 pregnant dalteparin-users and 29 pregnant healthy controls did not find significant decrease in BMD associated with long-term prophylactic dalteparin use [24], neither another observational study with 55 pregnant women on dalteparin and 20 pregnant healthy controls [25].

On the other hand one study in 61 pregnant women with prophylactic enoxaparin medication found, that Z-score in the lumbar spine or hip was $>1$ SD below the mean in $32 \%$ of the women, concluding that the effects on bone demineralization require further investigation [26]. Another study with prophylactic enoxaparin in 16 pregnant women found, that the incidence of significant bone loss in the proximal femur ( $\geq 10 \%$ reduction in BMD) was $14 \%$ [27]. They, however, concluded that the prolonged use of enoxaparin may not cause significant bone loss during pregnancy.

These previous studies are not comparable with each other. Some compare BMD in women with LMWH-exposure to those with UFH-exposure during pregnancy, others compare BMD in pregnant women with LMWH-exposure to healthy pregnant women. There are also studies comparing BMD before and after the LMWH-exposure. The overall impression of the current literature is, that some negative effect to BMD after long-term LMWH-exposure during pregnancy may exist. However, there is no sufficient proof of this, because of the small sample sizes.
Based on our data contraception pill use associated positively with BMD in spine. The duration of contraceptive pill use was significantly shorter in the LMWH-group than in the control group, because combined oral contraceptives (COCs) are contraindicated after the first VTE. Estrogens have been found to be important factors in the regulation of bone metabolism by suppressing osteoclastogenesis and inhibiting bone resorption by osteoclasts [28]. A systematic review with 129 studies concerning hormonal contraception and bone metabolism [29] found, that COCs have no significant effects on BMD in adulthood. In adolescents, however, low dose COCs ( $<30 \mu \mathrm{g}$ ethinylestradiol) might be insufficient to support peak bone acquisition, while COCs with $>30 \mu$ g ethinylestradiol seem to have no effect on BMD. [29] However a review of 13 studies in women using low-dose COCs indicated favorable effect on BMD in 9 studies. [30].

A 1-4\% decrease in the whole body, spine and total hip BMD has been reported during normal pregnancy [31], and it accelerates during lactation, when maternal bone is the main calcium source in the breast milk [32]. During lactation 5-10\% loss in BMD in 2-6 months has been found, but it restores 6-12 months after breastfeeding through still unclear mechanisms [33]. No association between the number of pregnancies, the duration of lactation and subsequent osteoporosis has been found [34]. Our study differs from the majority of the previous ones in that the DEXA-measurement was taken noticeable later after pregnancy and lactation, at a time when bone remodeling may already be complete. Duration of lactation can vary considerably (from some months to more than a year) and longer time between delivery and DEXA measurement may disclose this confounding factor.

A strength of our study is that, to our knowledge, there are no previous studies on subsequent BMD measurement many years after prolonged LMWH-exposure. Though small, our sample size is still larger than that in previously published studies on this same issue with earlier DEXA-measurements [6,24-27]. Furthermore, all women were Caucasians and the DEXA analyses were carried out by the same equipment in the same hospital.

Our study has several limitations. Our control group remained much smaller than the LMWH group due to the logistic problems. Furthermore, we did not have baseline BMD before the LMWH-exposure, so comparison of possible BMD-alterations before and after the exposure was impossible. Considerable differences in age, BMI, and timing of DEXA existed between the groups. Information on some potential confounding factors such as vitamin D-intake, calcium supplement, exposure to sun and family history of osteoporosis was not included in the questionnaire. Because most women on LMWH had low prophylactic doses, our study is unable to determine whether higher doses could cause more reduction in BMD.

\section{Conclusions}

We found no significant association between prolonged use of LMWH during pregnancy and a decreased BMD, osteopenia, osteoporosis, or fractures. Prospective controlled studies with greater sample sizes comparing different LMWH-dosages and preparations are still called for. Indications for long-term LMWH-medication during pregnancy should be based on the current guidelines. BMD-measurement in lumbar spine could be considered after a LMWH-exposed pregnancy, at least if there are other risk factors for osteoporosis.

\section{Addendum}

Study design and concept were carried out by AT, RK, LL, PG and VMU. PG and VH did the data analysis and RK, AT and VH contributed to the interpretation of data. Manuscript was prepared by PG and RK, $\mathrm{AT}$ and $\mathrm{VH}$ contributed to the improvement of the manuscript. 


\section{Declaration of interests}

VMU and RK have participated congresses by sponsors Leopharma and Pfizer. PG has participated one congress by sponsor Pfizer. All other authors declare no competing interests.

\section{Funding}

Unrestricted grant from Pfizer (WS749669) and the personal grant from The National Graduate School of Clinical Investigation.

\section{Acknowledgements}

DEXA-measurements in controls were funded by unrestricted grant by Pfizer. We thank all the women who participated in this study and the National Graduate School of Clinical Investigation. We thank also Ms. Eija Kortelainen for assistance in data collection and organizing the DEXA-analysis and Mr. Szabolcs Galambosi for help in data analysis.

\section{References}

[1] A.H. James, M.G. Jamison, L.R. Brancazio, E.R. Myers, Venous thromboembolism during pregnancy and the postpartum period: incidence, risk factors, and mortality, Am. J. Obstet. Gynecol. 194 (2006) 1311-1315.

[2] N. Kent, L. Leduc, J. Crane, D. Farine, S. Hodges, G.J. Reid, J. Van Aerde, Prevention and treatment of venous thromboembolism (VTE) in obstetrics, J. SOGC 22 (2000) 736-749.

[3] A. Kher, R. Bauersachs, J.D. Nielsen, The management of thrombosis in pregnancy: role of low-molecular-weight heparin, Thromb. Haemost. 97 (2007) 505-513.

[4] S.M. Bates, I.A. Greer, S. Middeldorp, D.L. Veenstra, A.M. Prabulos, P.O. Vandvik, American College of Chest Physicians, VTE, thrombophilia, antithrombotic therapy, and pregnancy: Antithrombotic Therapy and Prevention of Thrombosis, 9th ed: American College of Chest Physicians Evidence-Based Clinical Practice Guidelines, Chest 141 (2012) e691S-e736S.

[5] A. James, Committee on Practice Bulletins-Obstetrics, Practice bulletin no. 123: thromboembolism in pregnancy, Obstet. Gynecol. 118 (2011) 718-729.

[6] V. Pettila, P. Leinonen, A. Markkola, V. Hiilesmaa, R. Kaaja, Postpartum bone mineral density in women treated for thromboprophylaxis with unfractionated heparin or LMW heparin, Thromb. Haemost. 87 (2002) 182-186.

[7] L.A. Barbour, S.D. Kick, J.F. Steiner, M.E. LoVerde, L.N. Heddleston, J.L. Lear, A.E. Barón, P.L. Barton, A prospective study of heparin-induced osteoporosis in pregnancy using bone densitometry, Am. J. Obstet. Gynecol. 170 (1994) 862-869.

[8] T.C. Dahlman, H.E. Sjoberg, H. Ringertz, Bone mineral density during long-term prophylaxis with heparin in pregnancy, Am. J. Obstet. Gynecol. 170 (1994) 1315-1320.

[9] J.D. Douketis, J.S. Ginsberg, R.F. Burrows, E.K. Duku, C.E. Webber, P. Brill-Edwards, The effects of long-term heparin therapy during pregnancy on bone density. A prospective matched cohort study, Thromb. Haemost. 75 (1996) 254-257.

[10] M. Backos, R. Rai, E. Thomas, M. Murphy, C. Dore, L. Regan, Bone density changes in pregnant women treated with heparin: a prospective, longitudinal study, Hum. Reprod. 14 (1999) 2876-2880.

[11] I.A. Greer, Thrombosis in pregnancy: updates in diagnosis and management, Hematology Am. Soc. Hematol. Educ. Program 2012 (2012) 203-207.

[12] Assessment of fracture risk and its application to screening for postmenopausal osteoporosis, Report of a WHO Study Group, World Health Organ Tech Rep, Vol. 843 1994, pp. 1-129.
[13] J.M. Muir, M. Andrew, J. Hirsh, J.I. Weitz, E. Young, P. Deschamps, S.G. Shaughnessy, Histomorphometric analysis of the effects of standard heparin on trabecular bone in vivo, Blood 88 (1996) 1314-1320.

[14] T.C. Dahlman, Osteoporotic fractures and the recurrence of thromboembolism during pregnancy and the puerperium in 184 women undergoing thromboprophylaxis with heparin, Am. J. Obstet. Gynecol. 168 (1993) 1265-1270.

[15] R. Rajgopal, M. Bear, M.K. Butcher, S.G. Shaughnessy, The effects of heparin and low molecular weight heparins on bone, Thromb. Res. 122 (2008) 293-298.

[16] National Institute for Health and Welfare, Nutrition Unit, Fineli: Finnish food composition database(Release 16. 2013; Available at:) http://www.fineli.fi2015.

[17] B. Buehring, R. Viswanathan, N. Binkley, W. Busse, Glucocorticoid-induced osteoporosis: an update on effects and management, J. Allergy Clin. Immunol. 132 (2013) 1019-1030.

[18] F.J. Wu, S.Y. Sheu, H.C. Lin, Osteoporosis is associated with antiepileptic drugs: a population-based study, Epileptic Disord. 16 (2014) 333-342.

[19] R. Soriano, S. Herrera, X. Nogues, A. Diez-Perez, Current and future treatments of secondary osteoporosis, Best Pract. Res. Clin. Endocrinol. Metab. 28 (2014) 885-894.

[20] O.N. Nadhem, G. Azeez, R.D. Smalligan, S. Urban, Review and practice guidelines for celiac disease in 2014, Postgrad. Med. 23 (2015) 1-7.

[21] H. Casele, E.I. Haney, A. James, K. Rosene-Montella, M. Carson, Bone density changes in women who receive thromboprophylaxis in pregnancy, Am. J. Obstet. Gynecol. 195 (2006) 1109-1113.

[22] E. Lefkou, M. Khamashta, G. Hampson, B.J. Hunt, Review: low-molecular-weight heparin-induced osteoporosis and osteoporotic fractures: a myth or an existing entity? Lupus 19 (2010) 3-12.

[23] D. Ozdemir, A.A. Tam, A. Dirikoc, R. Ersoy, B. Cakir, Postpartum osteoporosis and vertebral fractures in two patients treated with enoxaparin during pregnancy, Osteoporos. Int. 26 (2015) 415-418.

[24] M.A. Rodger, S.R. Kahn, A. Cranney, A. Hodsman, M.J. Kovacs, A.M. Clement, A. LazoLangner, W.M. Hague, TIPPS investigators, Long-term dalteparin in pregnancy not associated with a decrease in bone mineral density: substudy of a randomized controlled trial, J. Thromb. Haemost. 5 (2007) 1600-1606.

[25] A.J. Carlin, R.G. Farquharson, S.M. Quenby, J. Topping, W.D. Fraser, Prospective observational study of bone mineral density during pregnancy: low molecular weight heparin versus control, Hum. Reprod. 19 (2004) 1211-1214.

[26] C. Nelson-Piercy, E.A. Letsky, M. de Swiet, Low-molecular-weight heparin for obstetric thromboprophylaxis: experience of sixty-nine pregnancies in sixty-one women at high risk, Am. J. Obstet. Gynecol. 176 (1997) 1062-1068.

[27] H.L. Casele, S.A. Laifer, Prospective evaluation of bone density in pregnant women receiving the low molecular weight heparin enoxaparin sodium, J. Matern. Fetal Med. 9 (2000) 122-125.

[28] F.P. Chen, K.C. Wang, J.D. Huang, Effect of estrogen on the activity and growth of human osteoclasts in vitro, Taiwan. J. Obstet. Gynecol. 48 (2009) 350-355.

[29] C. Nappi, G. Bifulco, G.A. Tommaselli, V. Gargano, C. Di Carlo, Hormonal contraception and bone metabolism: a systematic review, Contraception 86 (2012) 606-621.

[30] W. Kuohung, L. Borgatta, P. Stubblefield, Low-dose oral contraceptives and bone mineral density: an evidence-based analysis, Contraception 61 (2000) 77-82.

[31] H. Olausson, M.A. Laskey, G.R. Goldberg, A. Prentice, Changes in bone mineral status and bone size during pregnancy and the influences of body weight and calcium intake, Am. J. Clin. Nutr. 88 (2008) 1032-1039.

[32] C.S. Kovacs, Calcium and bone metabolism disorders during pregnancy and lactation, Endocrinol. Metab. Clin. N. Am. 40 (2011) 795-826.

[33] F. Polatti, E. Capuzzo, F. Viazzo, R. Colleoni, C. Klersy, Bone mineral changes during and after lactation, Obstet. Gynecol. 94 (1999) 52-56.

[34] S. Ip, M. Chung, G. Raman, P. Chew, N. Magula, D. DeVine, T. Trikalinos, J. Lau, Breastfeeding and maternal and infant health outcomes in developed countries, Evid. Rep. Technol. Assess. 153 (2010) 1-186. 